Acknowledgements: Medical writing services provided by Alan Saltzman of Fishawack Facilitate Ltd, part of Fishawack Health, and funded by AbbVie. The design, study conduct, and financial support for the study were provided by AbbVie. AbbVie participated in the interpretation of data, review, and approval of the abstract. No honoraria or payments were made for authorship.

Disclosure of Interests: Atul Deodhar Speakers bureau: Novartis, Pfizer, Consultant of: Novartis, Pfizer, AbbVie, Eli Lilly, UCB Pharma, GlaxoSmithKline, Galapagos, Janssen, Boehringer Ingelheim, Celgene, Amgen, Grant/ research support from: Novartis, Pfizer, AbbVie, Eli Lilly, UCB Pharma, GlaxoSmithKline, Denise Kruzikas Shareholder of: AbbVie, Employee of: AbbVie, Lili Zhou Employee of: AbbVie, Ana Biljan Shareholder of: AbbVie, Employee of: AbbVie, Christopher Saffore Shareholder of: AbbVie, Employee of: AbbVie

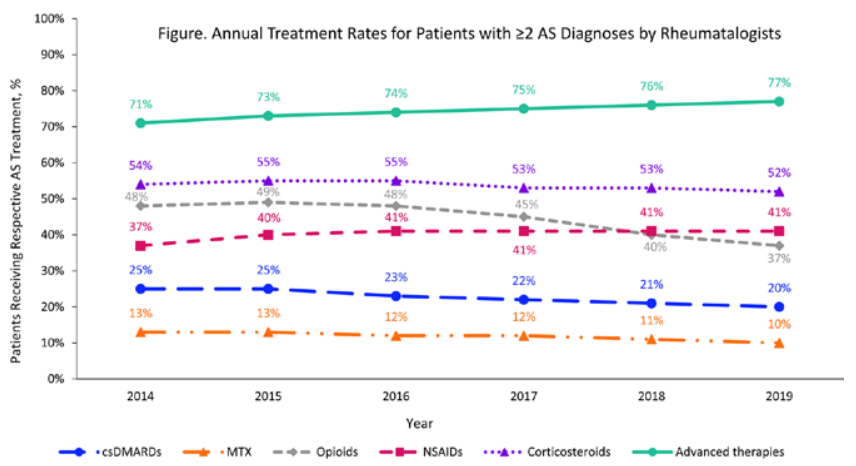

Figure 1.

DOI: 10.1136/annrheumdis-2021-eular.202

\section{POS0944 \\ AGE AT ONSET IN AXIAL SPONDYLOARTHRITIS AROUND THE WORLD: DATA FROM THE INTERNATIONAL ASAS-PERSPA STUDY}

A. Boel ${ }^{1}$, C. López-Medina ${ }^{2}$, D. Van der Heijde ${ }^{1}$, F. A. Van Gaalen ${ }^{1}{ }^{1}{ }^{1}$ Leiden University Medical Centre, Rheumatology, Leiden, Netherlands; ${ }^{2}$ Cochin Hospital, Assistance Publique Hôpitaux de Paris, Rheumatology, Paris, France

Background: Axial spondyloarthritis (axSpA) typically begins in young adulthood and age at onset is therefore very useful in identifying chronic back patients at an increased risk of axSpA. Age at onset below the age of 45 has been incorporated into the 2009 ASAS classification criteria for axSpA as a mandatory feature. However, inclusion of age at onset before the age of 45 was based on a small number of Western European studies and it is therefore unknown if this age at onset applies to patients in other parts of the world.

Objectives: The aim of this study was to assess age at onset of axSpA as well as its relationship with HLA-B27 throughout the world, using data from the Assessment in SpondyloArthritis international Society (ASAS) peripheral involvement in Spondyloarthritis (ASAS-perSpA) study.

Methods: Analyses were restricted to patients with an axSpA diagnosis who had information available on age at onset of axial complaints. Cumulative probability plots were used to graphically display the cumulative distribution of age at onset of axial symptoms. Linear regression models were built to assess

Table 1. Percentage of axSpA patients with an age at onset of axial symptoms $<40,<45$ and $<50$ years stratified by geographical region and HLA-B27 status.

\begin{tabular}{|c|c|c|c|c|c|c|c|c|}
\hline & \multicolumn{4}{|c|}{ HLA-B27 positive } & \multicolumn{4}{|c|}{ HLA-B27 negative } \\
\hline & $N$ & $\begin{array}{c}\text { Age at } \\
\text { onset }<40\end{array}$ & $\begin{array}{c}\text { Age at } \\
\text { onset }<45\end{array}$ & $\begin{array}{c}\text { Age at } \\
\text { onset }<50\end{array}$ & $N$ & $\begin{array}{c}\text { Age at } \\
\text { onset }<40\end{array}$ & $\begin{array}{c}\text { Age at } \\
\text { onset }<45\end{array}$ & $\begin{array}{c}\text { Age at } \\
\text { onset }<50\end{array}$ \\
\hline Asia & 469 & $91 \%$ & $94 \%$ & $97 \%$ & 56 & $79 \%$ & $88 \%$ & $95 \%$ \\
\hline $\begin{array}{l}\text { Europe \& } \\
\text { North } \\
\text { America }\end{array}$ & 678 & $88 \%$ & $94 \%$ & $98 \%$ & 184 & $74 \%$ & $85 \%$ & $93 \%$ \\
\hline Latin America & 157 & $81 \%$ & $94 \%$ & $96 \%$ & 38 & $45 \%$ & $76 \%$ & $84 \%$ \\
\hline $\begin{array}{l}\text { Middle East } \\
\text { \& North } \\
\text { Africa }\end{array}$ & 320 & $88 \%$ & $94 \%$ & $98 \%$ & 161 & $84 \%$ & $88 \%$ & $94 \%$ \\
\hline Total & 1624 & $88 \%$ & $94 \%$ & $97 \%$ & 439 & $76 \%$ & $86 \%$ & $93 \%$ \\
\hline
\end{tabular}

the effect of HLA-B27 status on age at onset of axial symptoms. As axSpA is a multifactorial, multigenetic disease, geographical region was investigated as an effect modifier.

Results: The majority (92\%) of patients with axSpA had an age at onset of axial symptoms below 45 years, with only small variation across the various geographical regions (table 1). Cumulative distribution plots showed age at onset of axial symptoms was consistently lower in HLA-B27 positive patients (in blue) than in HLA-B27 negative patients (in red) across all geographical regions (Figure 1 below). Linear regression models showed a significant effect of HLA-B27 status on the age at onset of axial symptoms in the total study population $(p<0.001)$, and Latin American $(p<0.001)$, European \& North American $(p<0.001)$, Asian $(p=0.006)$ and Middle Eastern \& North African $(p=0.005)$ populations. There was no effect modification of geographical region $(p=0.50)$ on the association between HLA-B27 status and age at onset of axial symptoms.

Conclusion: Irrespective of geographical region, the majority of axSpA patients had an age at onset of axial disease before the age of 45 . In all populations, HLA-B27 was associated with earlier disease onset. These results provide crucial data for diagnosis, classification, and policies aimed at improving recognition of $\operatorname{axSpA}$.

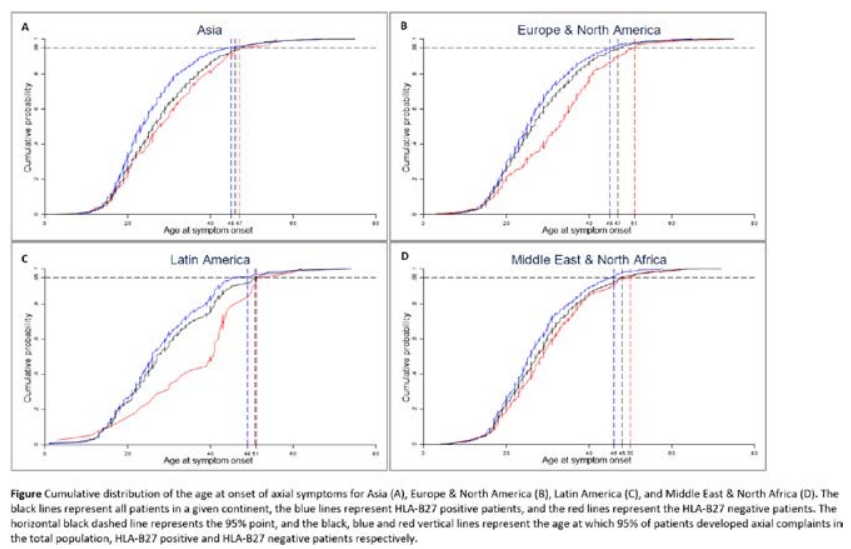

Figure 1.

Acknowledgements: We would like to thank all ASAS-perSpA investigators and members of the scientific committee

Disclosure of Interests: None declared

DOI: 10.1136/annrheumdis-2021-eular.218

\section{POS0945 NON-RADIOGRAPHIC AXIAL SPONDYLOARTHRITIS IN THE AFRO-CARIBBEAN POPULATION, CLINICAL ASPECTS AND PARTICULARITIES}

F. Louis-Sidney ${ }^{1}$, D. Morillon ${ }^{2}$, M. Blettery ${ }^{1}$, L. Brunier ${ }^{1}$, P. Numeric ${ }^{3}$, M. De Bandt ${ }^{2}{ }^{1}$ Hopital La Maynard Martinique, Rheumatology, Fort-de-France, Martinique; ${ }^{2}$ Hopital La Maynard Martinique, Radiology, Fort-de-France, Martinique; ${ }^{3}$ Hopital La Maynard Martinique, Rheumatology, Fort-de-France, Martinique

Background: Spondyloarthritis is a polymorphic disease and the absence of diagnostic marker has led to propose diagnostic criteria for recognition All the criteria, established in Caucasian populations, place at the center of the approach sacroiliac imaging and genetic terrain (HLA B27). For this reason, these criteria are not appropriate in populations lacking HLA B27. SPA is known to be rare in African populations and this rarity correlates with that of HLA B27.Prevalence of B27 in French West Indies is $2 \%$ (identical to the African populations)

Objectives: We report clinical manifestations of $\mathrm{SpA}$ seen at the Fort de France University Hospital, with an emphasis on the so-called "non-radiographic SpA" (NRSPA).

Methods: Adult patients with spondyloarthritis seen over a period of three consecutive months, were invited to participate in a survey and filled-in a self-administered questionnaire. The consulting rheumatologist specified the rheumatologic and extra-articular involvement, BASDAI score, HLAB27 data, markers of inflammation and imaging. 